\title{
THE ROLE OF ULTRASOUND AND COLOR DOPPLER IN PREDICTION OF PLACENTAL MYOMETRIAL INVASION IN WOMEN WITH PLACENTA PREVIA AND A PRIOR CESAREAN DELIVERY
}

By

\section{Sayed Muhammad Kamel ${ }^{1}$, Yehia Abd El-Salam Wafaa ${ }^{2}$ and Hosam El- Din Fahem Abd El-Raheem²}

\author{
${ }^{1}$ Obstetrics \& Gynecology Department, El-Galaa Teaching Maternity Hospital, Egypt
}

${ }^{2}$ Obstetrics \& Gynecology Department, Faculty of Medicine, Al-Azhar University, Egypt

Corresponding author: Sayed Muhammad Kamel, Mobile: 01225052636

E-mail: sayedkame1986@gmail.com

\begin{abstract}
Background: Placenta accreta is considered a life-threatening condition and the main cause of maternal mortality, postpartum hysterectomy, admission to ICU, and an inadvertent laceration to intestine or bladder during cesarean section.

Objectives: To evaluate the efficacy of transabdominal ultrasonography and color Doppler in prediction of placental myometrial invasion in patients with prior cesarean delivery.

Patients and methods: This prospective study was conducted at El-Galaa teaching maternity hospital in ultrasound unit, emergency department, and operation theatre where 100 pregnant women with gestational age of 30 weeks or more whose placentae were anterior and previa with previous cesarean deliveries by Trans abdominal real-time imaging

Results: Sensitivity, specificity, PPV, NPV, and accuracy of ultrasound in diagnosis of PA were $92.5 \%$, $90.0 \%, 86.0 \%, 94.7 \%$, and $91.0 \%$, respectively. The detection of intraplacental lacunae has the highest positive predictive value (95.5\%). with high sensitivity (92\%).

Conclusion: The presence of intraplacental lacunae had the highest sensitivity for detection of PA and the use of a two-criteria system allowed a good compromise between sensitivity and specificity, with high PPV and NPV.
\end{abstract}

Keywords: Placenta Previa, placental myometrial invasion, cesrarean section.

\section{INTRODUCTION}

Placenta accreta was first described nearly 80 years ago as a clinicopathological condition in which the placenta fails to separate partially or totally from the uterine wall. Several concepts have been proposed to explain why and how it occurs. In the past, it was thought that a primary defect of the biological function of the trophoblast would lead to excessive invasion of the myometrium by placental tissue beyond the physiological decidual-myometrial junction zone (Jauniaux and Jurkovic, 2012). 
Depending on the depth of trophoblast invasion into the myometrium, three subtypes have been differentiated: (1) superficial placenta accreta (also called placenta creta, vera, or adherenta), where the villi attach directly to the surface of the myometrium without invading it; (2) placenta increta, where the villi penetrate deeply into the myometrium up to the external layer; and (3) placenta percreta, where the invasive villous tissue reaches and penetrates through the uterine serosa (Jauniaux et al., 2018).

Placenta increta and percreta are often referred to as abnormally invasive placenta. More invasive placentation is not due to a further invasion of extra villous trophoblast in the uterine wall, but likely arises from an extended scar defect that allows the development of chorionic villi deep within the uterine wall, including within its peripheral circulation. The striking rise in the incidence of abnormally adherent and invasive placentation in women with a prior cesarean delivery supports the latter concept (Parra-Herran and Djordjevic, 2016).

Owing to the lack of international consensus on nomenclature, Jauniaux et al. (2018) suggested the term "Placenta Accreta Spectrum" (PAS) as a general term that includes both abnormal adherence and abnormal invasion.

The diagnosis of PAS is usually established by ultrasonography and the features suggestive of placenta accreta include vascular spaces within the placenta, thinning of the myometrium overlying the placenta, loss of the retroplacental "clear space", protrusion of the placenta into the bladder, increased vascularity of the uterine serosa and turbulent blood flow through the lacunae on Doppler ultrasonography (Little and rock well, 2012).

We aimed in this study to evaluate the efficacy of Trans abdominal ultrasonography and color Doppler in prediction of placental myometrial invasion in patients with prior cesarean delivery when the implantation site was in potential proximity to the scar to allow for adaptive preoperative management and surgical planning, and correlation of ultrasound and color Doppler data with the intraoperative findings.

\section{PATIENTS AND METHODS}

This prospective study was conducted at El-Galaa teaching maternity hospital in ultrasound unit, emergency department and operation theatre where 100 pregnant women with gestational age of 30 weeks or more whose placentas are anterior and previa with previous cesarean deliveries by trans abdominal real-time imaging during 3 years period from $\left(1^{\text {st }}\right.$ of December 2015 to $30^{\text {th }}$ November 2018).

Inclusion criteria included patients who presented with or gave history of third trimester bleeding coming for routine antenatal care, patients with previous cesarean delivery scheduled for repeated cesarean section whether electively or as an emergency and patients whose placentas were anterior, or previa including anterior low-lying defined as within $2 \mathrm{~cm}$ of the internal os by trans abdominal real-time imaging.

Exclusion criteria included posterior or fundal placentae and other uterine surgery besides previous cesarean section. 
THE ROLE OF ULTRASOUND AND COLOR DOPPLER IN PREDICTION... 707

All pregnant women were subjected to complete history, general and abdominal examination.

Ultrasound examination was done for signs of abnormal adherent placenta in the form of absence of the normally visible retroplacental hypoechoic zone, presence of placental sonolucent spaces (with their pattern of distribution), or irregularities of the bladder-uterine serosa were noted. Measurement of the smallest myometrial thickness (SMT) was obtained and it represented the area of greatest attenuation or thinning of the myometrium at the site of placental implantation.

All cases were subjected to transabdominal color Doppler to evaluate the variable uteroplacental vascular morphological patterns. Special attention was paid to the placental-myometrial interface and the placentas, in cases of previa were also evaluated for the presence of large abnormal intraplacental lakes.

\section{Ethical committee approval:}

The aim and nature of the study were explained for each patient before inclusion. Informed consents were obtained from patients.

\section{Statistical analysis of the data:}

Statistical analysis was done using IBM $^{\odot}$ SPSS $^{\odot}$ Statistics version $22\left(\right.$ IBM $^{\odot}$ Corp., Armonk, NY, USA). Numerical data were expressed as mean and standard deviation or median and range as appropriate. Qualitative data were expressed as frequency and percentage. Chi-square test (Fisher's exact test) was used to examine the relation between qualitative variables. For quantitative data, comparison between two groups was done using independent sample t-test or MannWhitney test. McNemar test was used to test concordance between ultrasound and operative diagnosis of placental accreta. Furthermore, the overall diagnostic accuracy of ultrasound criteria of placenta ccrete was assessed by computing summary estimates of sensitivity, specificity, positive and negative predictive values (PPV and NPV). A pvalue $<0.05$ was considered significant.

\section{RESULTS}

The intraplacental vascular lacunae were present in 39 patients. The bladder wall was highly vascular in 34 patients. Thin myometrium was detected in 45 patients. Interrupted hypoechoic retroplacental zone were present in 42 patients. Exophytic focal mass invading bladder wall were present in 5 patients (Table 1). 
Table (1): Ultrasound diagnosis of signs of placenta accrete

\begin{tabular}{|c|c|c|}
\hline Signs $\quad$ Groups & Number & Percentage \\
\hline Interrupted hypoechoic retroplacental zone & 42 & 42 \\
\hline Intraplacental lacunae & 39 & 39.0 \\
\hline Placental- bladder interface hypervascularity & 34 & 34.0 \\
\hline Thin myometrium & 45 & 45.0 \\
\hline Presence of exophytic focal mass invading bladder wall & 5 & 5.0 \\
\hline
\end{tabular}

There was no significant difference between ultrasound and operative diagnosis of placenta accreta $(\mathrm{p}=0.505)$.
Accordingly, sensitivity of ultrasound for diagnosis of placenta accreto was $92.5 \%$ (Table 2).

Table (2): Relation between ultrasound diagnosis of placenta ccrete and operative findings

\begin{tabular}{|c|c|c|}
\hline Operative Findings & \multicolumn{2}{|c|}{} \\
& Accreta & No Accreta \\
\hline Ultrasound Findings & $37(86.0 \%)$ & $6(14.0 \%)$ \\
\hline Accreta & $3(5.3 \%)$ & $54(94.7 \%)$ \\
\hline
\end{tabular}

Patients who needed hysterectomy were $24 \%$, Patients admitted to ICU were $33 \%$, Patients who needed blood transfusion were $45 \%$, Second laparotomy was $2 \%$, Bladder Injury was $8 \%$ and Mortality was $1 \%$ (Table 3).

Table (3): Outcome of surgical management of the studied group

\begin{tabular}{|l|c|c|}
\hline Group & Number & Percentage \\
\hline Patients who needed hysterectomy & 24 & $24.0 \%$ \\
\hline Patients admitted to ICU & 33 & $33.0 \%$ \\
\hline Patients who needed blood transfusion & 45 & $45.0 \%$ \\
\hline Second laparotomy & 2 & $2.0 \%$ \\
\hline Bladder Injury & 8 & $8.0 \%$ \\
\hline Mortality & 1 & $1.0 \%$ \\
\hline
\end{tabular}

The sensitivity of ultrasound detection of Intraplacental lacunae for diagnosis of placenta accreta had the highest sensitivity and specificity (92\% and 94\%) (Table 4).

Table (4): Diagnostic performance of the ultrasound criteria

\begin{tabular}{|l|c|c|c|c|c|}
\hline Performance Diagnosis & Sensitivity & Specificity & PPV & NPV & Accuracy \\
\hline $\begin{array}{l}\text { Interrupted hypoechoic } \\
\text { retroplacental zone }\end{array}$ & $80.6 \%$ & $79.7 \%$ & $69.0 \%$ & $87.9 \%$ & $80.0 \%$ \\
\hline Intraplacental lacunae & $92 \%$ & $94 \%$ & $97.4 \%$ & $96.7 \%$ & $96 \%$ \\
\hline Highly vascular bladder wall & $63.9 \%$ & $82.8 \%$ & $67.6 \%$ & $80.3 \%$ & $76.0 \%$ \\
\hline Thin myometrium & $83.3 \%$ & $76.6 \%$ & $66.7 \%$ & $89.1 \%$ & $79.0 \%$ \\
\hline $\begin{array}{l}\text { Exophytic focal mass } \\
\text { invading bladder wall }\end{array}$ & $12.8 \%$ & $93.4 \%$ & $80 \%$ & $63.8 \%$ & $64 \%$ \\
\hline
\end{tabular}


THE ROLE OF ULTRASOUND AND COLOR DOPPLER IN PREDICTION... 709

\section{DISCUSSION}

Placenta accreta (PA) occurs when the chorionic villi invade the myometrium abnormally. It is divided into three grades based on histopathology: placenta accreta where the chorionic villi are in contact with the myometrium, placenta increta where the chorionic villi invade the myometrium, and placenta percreta where the chorionic villi penetrate the uterine serosa (Carnevaleet al., 2011).

The risk of placenta accreta is $24 \%$ in women with placenta previa and one prior Cesarean delivery and $67 \%$ in women with placenta previa and three or more prior Cesarean deliveries (Chu et al., 2019).

Ultrasonography (US) has been the primary diagnostic tool for PA and has been shown to help detect this disorder in $50 \%-80 \%$ of cases (Maher et al., 2013).

There has been a long-standing interest in US screening for PA. US findings were first presented by Kerr de Mendonca in 1988 and Finberg and Williams in 1992. The rising cesarean section rate and resultant increased prevalence of PA have revived interest in the US features of this disorder (Srisajjakul et al., 2014).

The results of the current study demonstrated that sensitivity; specificity, PPV, NPV, and accuracy of ultrasound in diagnosis of PA were $80.6 \%, 78.1 \%$, $67.4 \%, 87.7 \%$, and $79.0 \%$, respectively. The presence of thin myometrium had the highest sensitivity (83.3\%). Cali et al. (2013) evaluated the diagnostic accuracy of gray-scale and color Doppler sonographic criteria for PA in 187 patients with placenta previa and history of uterine surgery. They used loss/irregularity of the echolucent area uteroplacental space, thinning or interruption of the hyperechoic interface between the uterine serosa and the bladder wall, the presence of placental lacunae, and hypervascularity of the uterine serosa-bladder wall interface. They detected PA in 41 patients on cesarean section. The criteria showed good diagnostic performance. Loss/irregularity of clear space used as a single criterion was responsible for the most false positives, demonstrating a low positive predictive value. Irregular intraplacental vascularization with tortuous confluent vessels affecting the entire width of the placenta, and hypervascularity of the entire uterine serosa-bladder wall interface, were only detected, on 3D power Doppler, in cases of placenta percreta.

In a more recent study, the sensitivity, specificity, PPV, NPV, and accuracy of loss of retroplacental clear were $87.3 \%$, $89.19 \%, 93.2 \%, 80.49 \%$, and $88 \%$; intraplacental lacunae were $93.65 \%$, $62.16 \%, 80.82 \%, 85.19 \%$, and $82 \%$; hypervascularity in uterine bladder interface were $47.62 \%, 94.59 \%, 93.75 \%$, $51.47 \%$, and $65 \%$; dilated vessels over peripheral subplacental zone were $82.54 \%, 81.08 \%, 88.14 \%, 73.17 \%$, and $82 \%$, respectively (Maged et al., 2018).

The use of a two-criteria system allowed for a good compromise between sensitivity and specificity, with high PPV and NPV. In our study according to two criteria system, sensitivity of ultrasound detection of interrupted hypoechoic retroplacental zone and Intraplacental lacunae for diagnosis of placenta accreta and Intraplacental lacunae was $86.3 \%$, thin myometrium and Intraplacental 
lacunae for diagnosis of placenta accreta and Intraplacental lacunae was $72.35 \%$, highly vascular bladder wall and Intraplacental lacunae for diagnosis of placenta accreta and Intraplacental lacunae was $77.95 \%$ and Exophytic focal mass invading bladder wall and Intraplacental lacunae for diagnosis of placenta accreta and Intraplacental lacunae was $61.98 \%$.

Pilloni et al. (2016) evaluated ultrasound in the diagnosis of PA based on two-criteria system of: loss/irregularity of the retroplacental clear zone, thinning/interruption of the uterine serosabladder wall interface, placental lacunae, myometrial thickness $<1 \mathrm{~mm}$, increased vascularity of the uterine serosa-bladder wall interface, loss of vascular arch parallel to the basal plate and/or irregular intraplacental vascularization. The twocriteria system identified 30 cases of PA with a sensitivity of $81.1 \%$ and specificity of $98.9 \%$ (Pilloni et al., 2016).

\section{CONCLUSION}

- The presence of intraplacental lacunae had the highest sensitivity for detection of PA.

- The use of a two-criteria system allowed for a good compromise between sensitivity and specificity, with high PPV and NPV.

\section{REFERENCES}

1. Cali G, Giambanco L, Puccio $G$ and Forlani F. (2013): Morbidly adherent placenta: evaluation of ultrasound diagnostic criteria and differentiation of placenta accreta from percreta. Ultrasound Obstet Gynecol Off J Int Soc Ultrasound Obstet Gynecol., 41:406-12.

2. Carnevale FC, Kondo MM and Oliveira W (2011): Perioperative temporary occlusion of the internal iliac arteries as prophylaxis in cesarean section at risk of hemorrhage in placenta accreta.Cardiovasc Intervent Radiol., 34(4):758-764.

3. Chu C, Zhao $S$ and Ding $M$ (2019): Combining Clinical Characteristics and Specific Magnetic Resonance Imaging Features to Predict Placenta Accreta. J Comput Assist Tomogr., 43(5):775-779.

4. Jauniaux $E$ and Jurkovic D. (2012): Placenta accreta: Pathogenesis of a 20th century iatrogenic uterine disease. Placenta., $33: 244-51$.

5. Jauniaux E, Collins $S$ and Burton GJ. (2018): Placenta accreta spectrum: pathophysiology and evidence-based anatomy for prenatal ultrasound imaging. Am J Obstet Gynecol., 218:75-87.

6. Little SH and Rockwell PG (2012): Ectopic pregnancy: zero in on these lab and imaging clues. J Fam Pract., 61(11):678-686.

7. Maged AM, Abdelaal H, Salah E, Saad H, Meshaal $H$ and Eldaly A. (2018): Prevalence and diagnostic accuracy of Doppler ultrasound of placenta accreta in Egypt. J Matern-Fetal Neonatal Med Off J Eur Assoc Perinat Med Fed Asia Ocean Perinat Soc Int Soc Perinat Obstet., 31:9339.

8. Maher MA, Abdelaziz A and Bazeed MF (2013): Diagnostic accuracy of ultrasound and MRI in the prenatal diagnosis of placenta accreta.Acta Obstet Gynecol Scand., 92(9):1017-1022.

9. Parra-Herran C and Djordjevic B. (2016): Histopathology of Placenta Creta: Chorionic Villi Intrusion into Myometrial Vascular Spaces and Extravillous Trophoblast Proliferation are Frequent and Specific Findings With Implications for Diagnosis and Pathogenesis. Int J Gynecol Pathol Off J Int Soc Gynecol Pathol., 35:497-508.

10. Pilloni E, Alemanno MG, Gaglioti P, Sciarrone A, Garofalo A and Biolcati $M$. (2016): Accuracy of ultrasound in antenatal diagnosis of placental attachment disorders. Ultrasound Obstet Gynecol Off J Int Soc Ultrasound Obstet Gynecol., 47:302-7.

11. Srisajjakul S, Prapaisilp $P$ and Bangchokdee S. (2014): MRI of placental adhesive disorder. $\mathrm{Br}$ J Radiol., 87(1042):20140294. 
دور الموجات فوق الصوتية والدوبلر الملون فى التنبوء

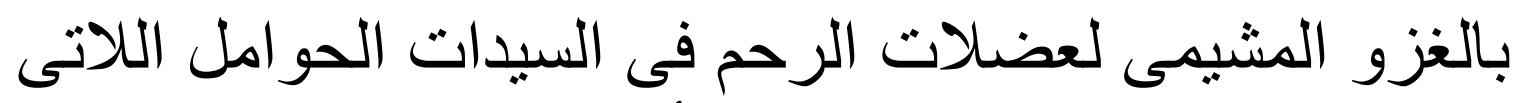
يعانين من وجود مشيمة متقدمة وأجريت لهن لهن عملية قيصرية سابقة

سيد محمد كامل زيدان*، يحيى عبد السلام وفـث** و حسام الدين فاهم عبد الرحيم**

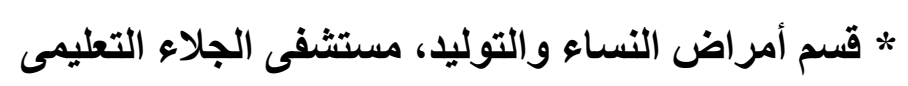

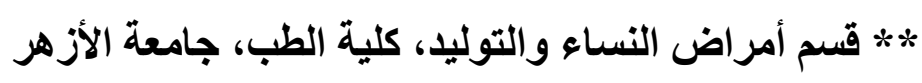

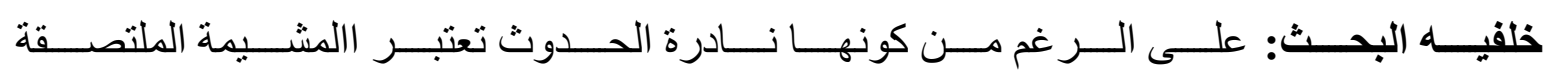

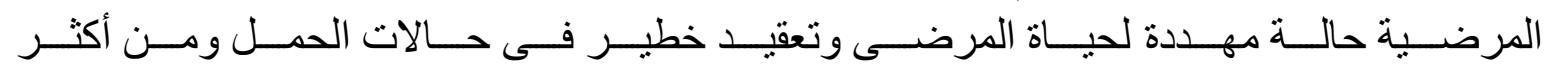
التعقيدات المسببة للنزيف الرحمى الثنديد بعد الولادة.

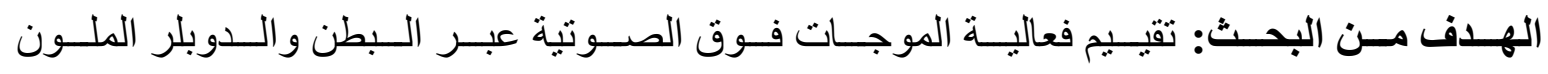

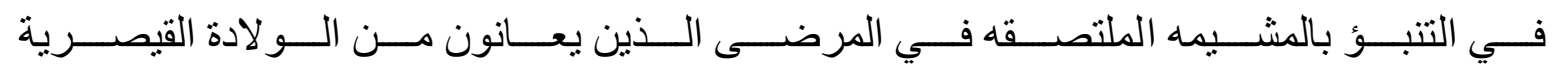

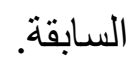

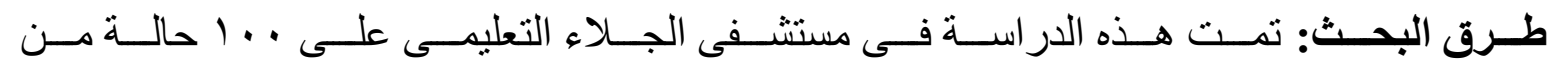

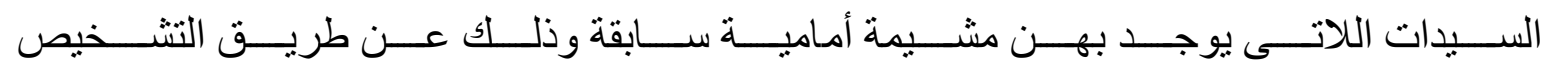

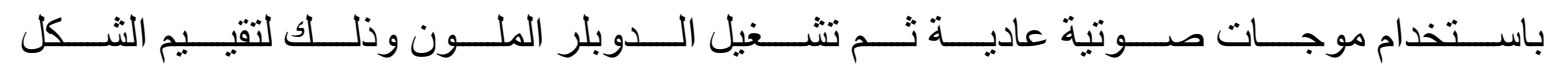
النمطى للأو عية الدموية فى الرحم و المشيمة وسريان الدم في الأوردة.

النتائج: كانت دقة السونار (الموجات الصوتية) فى التتخيص كالتالى:

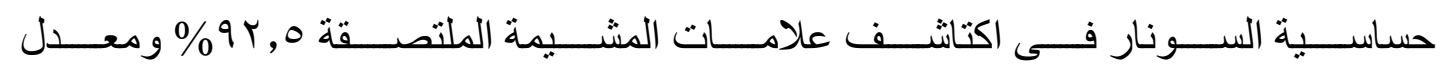

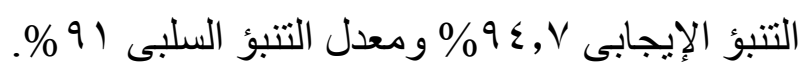

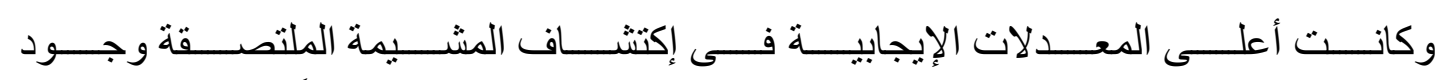

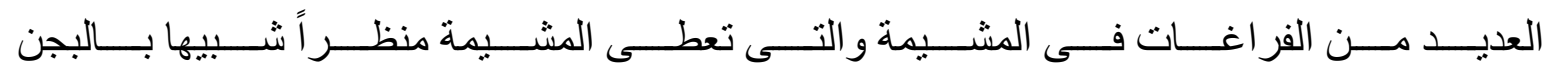

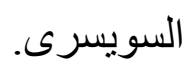

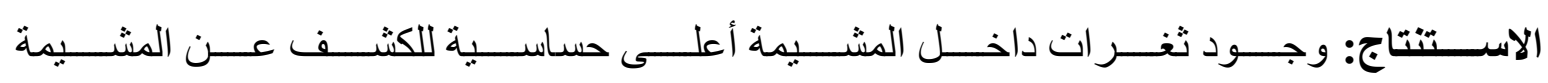

